This is an electronic reprint of the original article. This reprint may differ from the original in pagination and typographic detail.

Author(s): Leppänen, Sirpa

Title: Dog blogs as ventriloquism: Authentication of the human voice

Year: $\quad 2015$

Version:

Please cite the original version:

Leppänen, S. (2015). Dog blogs as ventriloquism: Authentication of the human voice.

Discourse, Context and Media, 8, 63-73. https://doi.org/10.1016/j.dcm.2015.05.005

All material supplied via JYX is protected by copyright and other intellectual property rights, and duplication or sale of all or part of any of the repository collections is not permitted, except that material may be duplicated by you for your research use or educational purposes in electronic or print form. You must obtain permission for any other use. Electronic or print copies may not be offered, whether for sale or otherwise to anyone who is not an authorised user. 


\section{TITLE PAGE}

Title:

DOG BLOGS AS VENTRILOQUISM: AUTHENTICATION OF THE HUMAN VOICE

Author name and affiliation:

Sirpa Leppänen

University of Jyväskylä

Department of Languages

P.O. Box 35

40014 University of Jyväskylä

Finland

sirpa.leppanen@jyu.fi 


\title{
DOG BLOGS AS VENTRILOQUISM: AUTHENTICATION OF THE HUMAN VOICE
}

\author{
Sirpa Leppänen \\ University of Jyväskylä
}

\begin{abstract}
This paper looks at personal blogging by dog owners in an international, English language blogsite in which dog owners from around the world report and reflect upon their dogs and their lives with dogs, and do so by using the dog's voice. It approaches dog blogs as an example of the strategic use of pervasive but contentious anthropomorphic western discourses about animals and discusses how dog bloggers use anthropomorphism as a discursive means for crafting and collectively ratifying authenticity in a translocal, interest-driven and informal social media context in which traditional territorial and demographic parameters of authenticity are not easily available or relevant.
\end{abstract}

More specifically, the paper shows how the discursive means for authentication in dog blogging entail deliberate acts of ventriloquism and stylization. It analyses the ways in which these function to authenticate bloggers socially and morally as legitimate participants in dog blogging and as particular kinds of persons. Further, it discusses how a range of norms associated with blogging, on the one hand, and historically specific discourses about humans and companion animals, on the other hand, are recontextualized for the purposes of the socio-cultural niche in question. Particular attention is paid to how linguistic and discursive features associated with diary writing, as well as to how western discourses of dogs and animals are mobilized in the establishment, maintenance and regulation of the global practice about dogs in a way that is highly indexical of idealized, classed gender.

Keywords: blogging, authentication, normativity, stylization, diary writing, dogs, anthropomorphism

Highlights:

- The global practice of blogging about dogs is an example of the significance of authentication in social media practice

- Authentication involves a social and moral dimension

- In informal, interest-based social media practices authentication requires consent, uptake and regulation of a particular discursive orientation

- In blogging about dogs discursive authentication involves stylization and ventriloquism

- In stylization and ventriloquism, bloggers mobilize linguistic and discursive features associated with diary writing and western discourses of dogs and the dog-human relationship

- Dog blogging is highly indexical of idealized, classed gender. 


\section{INTRODUCTION}

This paper looks at personal blogging by dog owners in an international, English language blogsite, Dogster, in which dog owners from around the world report and reflect on their dogs and their lives with dogs and do so by posing as their dogs. As cultural practice this is intriguing, because in its own way it highlights the pervasive and contentious practice of anthropomorphism in a cultural context where animal rights and agency, as well as human-animal relations are becoming increasingly topical (see, e.g. the collection of essays in Daston and Mittman 2005) and where they are debated and renegotiated in intercultural relations and in relation to global crises such as famine and global warming (see, e.g. Leonard 2014). For the purposes of this article, blogging about dogs is also an interesting case, because it can effectively highlight two fundamental and recurrent features of social media practice. The article shows that, while in translocal, interest-driven and informal social media practices traditional demographic and territorial parameters of authenticity are not easily available or relevant for participation and belonging, authenticity, as an effect of the process of authentication, still continues to be a central issue.

Hence, how authenticity is important in social media practices is the focus of this paper. Building on recent discourse-ethnographic work on identities and normativities in different social media environments (e.g. Leppänen 2008, 2009, 2012; Leppänen and Piirainen-Marsh 2009; Leppänen and Häkkinen 2013; Leppänen et al. 2014; Kytölä 2013), I will show how authenticity in social media practices is something that is deliberately discursively crafted and collectively ratified, a technology of the self in Foucault's (1988) sense whereby the adherence to a particular discourse produces selves that are desirable and appropriate in a particular context.

More specifically, the article discusses ways in which social media participants, to authenticate themselves and others (Bucholtz 2003; Bucholtz and Hall 2004) strategically orient to and mobilize distinctive linguistic and discursive choices conventionalized in their social media niche. It shows how in the case of dog blogging such discursive crafting involves deliberate acts of ventriloquism (Jacklin 2005), imposture (Kramsch 2012) and stylization (Rampton 1999). The article also shows how authentication in dog blogging involves a social and moral dimension: on the one hand, it makes possible that bloggers have access to and legitimacy in participating in blogging, and, on the other, ensures that they are people who have an appropriate moral outlook on and relationship with dogs. 
Authentication will thus be investigated as multi-voiced practice. The article will show in detail how a particular way of writing - the pretension to write like a dog -is seemingly used to persuade blog audiences to believe that it is the dog - and not the human - whose voice and style of writing we witness in the blogs. Thus, the fact that such an impression can be created actually authenticates the humans. In addition, the article will show how, in this process, a range of norms associated with blogging, on the one hand, and historically specific discourses about humans and companion dogs, on the other hand, are recontextualized for the needs and purposes of the socio-cultural niche in question. In these tasks, particular attention will be paid to how linguistic and discursive features associated with diary writing, as well as western discourses of anthropomorphism, are drawn on in the establishment, maintenance and regulation of this global genre of writing about dogs in a way that is highly indexical of human identities, classed gender, in particular.

\section{WHAT ARE DOG BLOGS, WHY ARE THEY WRITTEN AND HOW ARE THEY INTERESTING?}

Dog blogs, frequently updated webpages with dated entries (Blood 2002: 12) focusing on dogs, could be defined as a particular sub-genre of personal blogs (Walker Rettberg 2013: 20-1): they are written by individual, (mostly female) dog owners, in a style that ranges from informal to intimate, featuring a subjective and personal perspective. For the bloggers, they function as a medium to report on their dogs' lives, activities, experiences and emotions ${ }^{1}$, but also as means to convey the humans' emotional attachment to dogs, and to provide information and entertainment to likeminded dog lovers.

As in blogging in general (see e.g. Blood 2002:12; Bruns 2006: 70; Myers 2010:2; Walker Rettberger 2013: 18), dog blogging is, however, a much more varied and emergent phenomenon than the definition above suggests. While some of the blogs look more or less like personal diaries, other types include semi-professional, filter-type commentaries published on websites devoted to sharing information on dogs and to networking with other dog owners, or on dog owners’ personal websites, as well as essay-type blogs that can contain both external and personal content. At one extreme, there are professional blogs about dogs by dog breeders or trainers, in which the

\footnotetext{
1 According to a Nielsen/McKinsey company (2012), by the end of 2011, there were over 181 million blogs in the world, up from 36 million only five years earlier in 2006. Overall, 6.7 million people publish blogs on blogging websites, and another 12 million write blogs using their social networks. Most bloggers are women, and half of bloggers are aged 18-34 (http://www.nielsen.com/us/en/insights/news/2012/buzz-in-the-blogosphere-millions-morebloggers-and-blog-readers.html).
} 
dissemination and discussion of information about dogs' characteristics, training and care often is the main objective. Often, blogs like these can have some commercial agenda as well, as when particular services or paraphernalia are being marketed to dog owners. At the other extreme, there are blogs that represent and tell stories about dogs and life with dogs with an intention to please and entertain others who are interested in dogs. The blogs in focus in this article belong to this category, although they, too, can include or link to more factual or commercial aspects of dog rearing. Dog blogs also vary according to their narrative conventions in that they include texts that can use either the dog owner or the dog as the source of the information and the narrator of the stories told in the blogs. In this article, the latter type is discussed. Furthermore, dog blogs rarely are stand-alone monologues, but, again, as typical of blogs in general, they thrive on the orientation to, responses of and interaction with an audience (Walker Rettberger 2013: 21, 47). In this sense, they could be characterized as a particular type of interest-driven and informal social media communication (Leppänen and Kytölä, forthcoming).

Dog blogs are a popular genre. A simple Google search with the search words “dog blogs” yields 184000000 entries and “dog diaries” 15200000 entries (January 15, 2015). Dog blogs are also a global genre: although it is most popular in the US, it seems that they are also written by dog owners in other parts of the world (i.e. in places and cultures where dogs are appreciated as animals and pets) in different languages. As an illustration, Table (1) shows how on the international Dogster website, the source of the present data, there is information on over 500000 dogs from all over the world. The site markets itself as "a forum to share love of dogs virtually" and publishes information and advice on dogs and their care, breeding and training, and photos and stories about dogs, as well as providing various services (such as dog adoption service). It is operated by SAY Media, Inc., a privately held company in San Francisco, CA, USA.

Table 1: Most popular countries of residence of dogs in Dogster

\begin{tabular}{|l|l|}
\hline $\begin{array}{l}\text { Most popular countries of residence } \\
\text { of dogs presented in Dogster }\end{array}$ & Number \\
\hline United States & 410,124 \\
\hline Canada & 23,601 \\
\hline Philippines & 13,376 \\
\hline United Kingdom & 8,185 \\
\hline
\end{tabular}




\begin{tabular}{|l|l|}
\hline Australia & 5,429 \\
\hline Singapore & 2,695 \\
\hline Malaysia & 1,731 \\
\hline Indonesia & 1,553 \\
\hline Brazil & 1,097 \\
\hline New Zealand & 887 \\
\hline India & 817 \\
\hline Mexico -- & 736 \\
\hline Germany -- & 701 \\
\hline South Africa -- & 636 \\
\hline Netherlands -- & 594 \\
\hline
\end{tabular}

(www.dogster.com , accessed on January 16, 2015)

Out of all the dogs whose information is recorded in the Dogster website, 79769 dogs also have their own blog. In this international site practically all blogs are in English, which in its own way is a clear indication of how having dogs is a translocal and transcultural phenomenon, i.e. both locally meaningful and popular practice, and shared culture mediated, contributed to and upheld by digitally connected participants from different parts of the world.

The popularity of dog blogs, as well as the visibility of dogs themselves in social media, no doubt reflect the close and historically unique relationship that humans and dogs have had (Thurston 1996; Pietiläinen 2013). Simply put, dogs have been and continue to be valued companions, aids and protectors of humans. According to a survey on attitudes to dogs (Bonas et al. 2000: 219-25), this is shown, for example, in how pet dogs as companions of the human score higher than humans on a number of social or relational provisions such as providing reliable alliance, nurturance, and companionship, while human relationships score higher overall in terms of aggregating social support. In other words, people have come to rely increasingly on dogs as their significant or even primary means of social and emotional support (Katz 2003). For some (see e.g. Garber 1996), this may even mean that dogs are seen as what make us human.

The exceptional relationship of humans and dogs also shows in how, over time, dogs have become a particular symbolizing system to externalize and dramatize what humans think (Daston and Mittman 2005: 12). Thanks to their long history of domestication and co-habitation with humans, 
dogs have become handy metaphors with which humans can speak of themselves (Daston and Mittman 2005: 11) A good illustration of this is how in western cultural traditions dogs have long been used as protagonists and speaking subjects in fictional, entertaining, fantastic and moral stories - consider, for instance, Aesop's fables dating back to the Greek antiquity, medieval bestiaries, 17th century fables by LaFontaine, or modern fiction, comics and popular cinema (Daston 2005: 50-1; Pietiläinen 2013). According to Daston and Mittman (2005: 12-3), why dogs, or, more generally, animals, are in fact such a fertile symbolizing system has to do with their performativity: they are not static images of human projections, but through their embodied actions they actively, and to an extent in an agentive way, mobilize them in a way that humans find much more intriguing than, for example, flowers, dolls or robots. In this sense, blogs that use dogs to externalize and dramatize what humans think are a new variation of an age-old story. However, as I will show below, this adaptation is not only a continuation of what has always been there, but it also highlights how the tenacious trope of dogs is taken up and made to function as a particular means for authentication of human identity in a context in which other means of authentication are few or altogether absent.

\section{AUTHENTICATION, NORMATIVITY AND VENTRILOQUISM IN SOCIAL MEDIA}

As was argued above, the oxymoronic case of dogs writing about themselves is here used to highlight ways in which participants in social media niches orient to authenticity as an important socio-cultural value or ideology (Bucholtz 2003: 400), and how, in such niches where there often are few or no pre-given identity parameters guiding orientation to and interaction with others, authenticity is something that the participants need to deliberately signal to each other.

In terms of normativity, this means that identification in social media niches, such as dog blogging, is best seen as a discursive orientation towards sets of features that are or can be seen as emblematic of particular situated identities (Blommaert and Varis 2013). Further, as I will show in my analysis, such discursive orientations often involve positioning in relation to multiple centres of normativity competing with and complementing each other (Blommaert et al. 2005; Leppänen 2009; Blommaert 2010:37-39). Consequently, what we often witness in social media practices is late modern postPanopticon normativity in action (Arnaut 2012; see also Varis and Wang 2012; Leppänen et al. 2014), manifesting in the lack of centralised mechanisms of control by 'those in power' and in a shift to forms of peer policing of participant activities (Leppänen and Piirainen-Marsh 2009). Despite the polycentric and emergent nature of such forms of governmentality and normativity, 
they effectively hail social media participants and police them into communicative and social conformity (Leppänen 2009). In this way, I argue, dog blogs - or, more generally, social media discursive practices that demonstrate the emergence and gradual crystallization of new normativities - illustrate how issues of authenticity emerging in social media can respond to, speak of and contribute to social change (Coupland, in press).

Stepping into these theoretical footholds also implies that, instead of authenticity, it is really authentication (Bucholtz 2003; Bucholtz and Hall 2004; see also Nørreby and Møller in this issue; Kytölä and Westinen in this issue) that becomes both individually and collectively a central sociocultural practice in social media. In Bucholtz's words (2003: 408), authentication could be defined as follows:

Where authenticity presupposes that identity is primordial, authentication views it as the outcome of constantly negotiated social practices. [...] It is the tactic of authentication that produces authenticity as its effect. Thus sociolinguistics should speak not of authenticity but more accurately of authenticity effect, achieved through the authenticating practices of those who use and evaluate language. (Bucholtz 2003: 408)

Thus authenticity - here, a sense of being a legitimate participant or a member in a social media niche - can be achieved by mobilizing particular linguistic and other semiotic resources in ways that are foregrounded and reflexively taken as appropriate (see also Staehr in this issue) in the particular socio-cultural context.

What I will show in my analysis is that the practices with which dog bloggers can achieve an authenticity effect in the affinity space ${ }^{2}$ provided by Dogster crucially involve crafting discourse that strives, through seeming disauthentication of the writers as humans, to authenticate them as someone with a legitimate access and participation rights in dog blogging, but also, more generally, as people with a particular kind of moral and ideological orientation towards dogs, themselves and others. Again, I will also demonstrate how such seemingly abstruse practice can make a more general point about authentication. I will do so by highlighting ways in which authentication is constructed by putting up a multi-voiced performance in which, for example, a variety is artificially taken up and stylized by a speaker to whom the variety is not normally felt to belong (Rampton 1999: 501), and who thus performs a deliberate imposture, posing as someone who s/he is not (Kramsch 2012).

\footnotetext{
2 An affinity space refers to a location where groups of people are drawn together because of a shared, strong interest or engagement in a common activity (see e.g. Gee 2005).
} 
Authentication through stylization, or imposture, thus involves the mobilization of more than one voice, ('polyphony’, as defined by Bakhtin 1993). Following Bakhtin (1993: 15; see also Rampton 2006: 133), multi-voicedness can be seen to involve a variety of distinct (idiolectal, sociolectal, stylized) voices and representations of consciousness centripetally coming together more or less harmoniously in the production of unified discourse. Multi-voicedness has always been central in translocal, informal and interest based social media practices (Leppänen 2009; 2012; Leppänen et al. 2014; Kytölä forthcoming) that draw on, combine, recontextualize and resemiotize linguistic and discursive resources originating from diverse sources (e.g. languages, varieties, cultural traditions, geographical locations) for their niched purposes and audiences.

A form of multi-voicedness that has become particularly popular in social media practices recently involves what could be called ventriloquism (for a detailed discussion of the long history of ventriloquism in the Western culture, see Connor 2000). Once more, as a phenomenon ventriloquism is by no means limited to social media practices, but it is, in fact, a recurring feature of a range of contemporary discourse practices, such as collaboratively produced, or assisted writing in which the task involves the production of first-person narratives with the assistance of another or others (Jacklin 2005:1-2). Basically, in such ventriloquist practice, the participants, both producers and audience, engage, in Jacklin's words (2005: 2), in ”the simulation of voice dissociated from its source. That dissociation evokes awe and mystery, power and mastery, yet also implies an acknowledgement of its inherent deceit and its own impossibility.” To Jacklin (2005:2), the ventriloquist nature of collaborative writing explains why

assisted life writing has through the centuries of its production been both appealing and appalling in fairly equal measure. [...] [T] he metaphor of ventriloquism neatly captures the simultaneity of fascination and distaste readers experience in the consumption of the collaborative voice.

Following de Certeau (1988), Jacklin (2005) also emphasizes that voice is a product of tensions, of forces that draw and pull, of pressures that may be productive as well as obstructive. Further, he (2005: 13) argues, "[h]ow that voice reaches the page, from whom, with whom, through whom, for whom, because of whom, or in spite of whom all contributes to the inflections that may be detected”.

It is relatively easy to extend and recontextualize Connor's and Jackclin's arguments here, and argue that, like ventriloquism in general, and assisted life writing in particular, dog blogs engage in the simulation of a voice ridden by tensions and divisions, dissociated from its source, pervasively 
contaminated by the human voice and human perceptions and discourses about dogs, as well as inflected in ways that contribute to the perception of this kind of ventriloquist writing as both curiously fascinating and distasteful.

Importantly, dog blogs are not that exceptional as a form of ventriloquist social media practice. Other similar examples can easily be found. These include other popular practices that crucially build on entextualization and resemiotization (Leppänen et al. 2014) as key semiotic means for expression and communication. For instance, fan fiction imitating and appropriating cult discourses (Leppänen 2008, 2012), as well as buffalaxing and mashupping that simulate oriental others' and political figures’ voices (Leppänen and Häkkinen 2012) also in their own ways engage in ventriloquism where the voices of the original and of the ventriloquist are made to intermingle to create (multi-voiced and ambiguous) interventional fan culture, critical humour, and entertaining political critique and activism. In this sense, the ventriloquism of dog blogging draws on and is supported by an emergent and dynamically unravelling tradition.

To recap, the theoretical take of this paper on the key themes of this special issue is a problematizing one: rather than authenticity, it focuses on authentication. Rather than looking at features of discourse that could be taken to index in a straightforward way emblematic aspects of identity, it looks at ways in which, via a discursive orientation to a range of centres of normativity, an impression of authenticity is crafted and acknowledged. More specifically, such an authentication depends on deliberate ventriloquism, in which the human performs a stylization of the dog's imagined voice, and in which the dog serves as the human ventriloquist's dummy. Authentication and normativity are thus seen as intertwined with one another: authentication relies on the mobilizing discursive resources with which the human blogger can legitimately claim access to and right to participate as both a blogger and a particular kind of a person in the social space provided by the Dogster website. What I thus address specifically in this article are the discursive means bloggers use to authenticate their own dog blog production. In this investigation, normativity is a relevant concept, because of the striking similarities across the discursive means used by different bloggers from around the world. 


\section{HOW IS THE VENTRILOQUIST VOICE PRODUCED AND WHAT IS IT SAYING ABOUT HUMANS AND THEIR DOGS?}

In the following, I will show, with examples drawn from the Dogster website, how authentication is achieved in dog blogging, and what particular authenticity effects are thus created. I will focus on blogs written in English that use the dog's voice and perspective, by writers who are based in the United States, the United Kingdom, the Philippines and Finland. The reason these blogs are particularly interesting for the purposes of this article is that they demonstrate how in interestdriven and informal social media practices in which the contributors come from different parts of the world, the translocality and transculturality of the forms of participation have a decisive impact on authentication. In such social spheres in which, in principle, very little can initially be assumed of the identities of the other participants, it becomes necessary to authenticate oneself and others discursively, by establishing, maintaining, monitoring and regulating the ways in which participants can present themselves, craft their messages, choose the styles of communication and language, and orient to and interact with others. Often, such a situation leads to the emergence and collectively enforced complex normativities, ranging from very explicit (instructions, guidelines, etiquette, moderation, censorship, commentaries) to very implicit, to-be-inferred norms (preferred styles, language and other semiotic choices, forms of interaction); and from very specific, situated norms (such as site-specific, 'idiosyncratic' modes of discourse practice) through norms transferred from other settings (such as school) as well as to more general, socio-cultural norms (for more, see, e.g. Leppänen 2009; Kytölä 2013; Varis and Wang 2011).

In my analysis, drawing on discourse studies, and informed by my long-term ethnographic investment in the observation of informal and interest-driven social media practices, I will pay close attention to the contents, linguistic choices and discourse features that writers select to authenticate themselves as dog bloggers for the other contributors in the affinity space of Dogster. In my analysis I will here concentrate on investigating the blog entries only, excluding the comments and other responses (e.g. "likes”, “bones”, “rosettes”) by blog audiences. This decision is justified by my wish to show how the orientations in extended discourse, such as dog blogs, themselves illustrate the sociality of social media: how they respond to, contribute to and interact with the emergent norms and conventions of their social media affinity spaces (see above, also Leppänen 2009; Leppänen et al. 2014). 
Although the site is a public one, and the contributors use aliases to log on to the site, I will avoid referring to these aliases as well as to the dogs' names. This is because the data examples can give (and have given) rise to critical comments and even concerns about the kind of persons who actually engage in dog blogging ${ }^{3}$. Hence, by protecting the identities of the bloggers, I wish to minimize the risk of possible trolling or otherwise harmful comments to the bloggers' - in other words, to protect them from possible risks.

I will also show how the choices made by the bloggers incrementally contribute to the construction of a particular kind of authenticity that, at the outset, appears to promote and share unexpected versions of identity, but that, in the end, draw on and mobilize quite conservative discourses of identity, gender, class, and human-animal relationships. Along the lines suggested by Kramsch (2012), this kind of analysis is thus geared towards discussing whose voice/s it is that we hear in discourse, which discourses of truth are being drawn on and circulated, and in whose interests it is to engage in the specific ways of authentication witnessed in the data.

\subsection{Dogs keeping diaries}

The dog blogs in my data - typical representatives of English language blogs by writers based in the US, the UK, the Philippines and Finland - have all been published in Dogster during the past 10 years. Blogs by writers based in the US (c. 60 000), the UK (c. 1500 diaries) and the Philippines (c. 1500 diaries) are well represented overall in the website (see Table (1)), whereas blogs written by writers based in Finland are a small minority. Out of the 79769 dog blogs in Dogster only approximately twenty originate in Finland. ${ }^{4}$ Although a small minority, blogs by Finland-based writers are, however, interesting from the perspective of the sociolinguistic situation in Finland, as they seem to corroborate the overall picture of the role, uses and functions of English in contemporary Finland, (see e.g. Leppänen et al. 2009, 2011; Leppänen and Pahta 2012), showing bloggers', for whom English is an additional language, interest in and active engagement with translocal and transcultural digital practices in English.

\footnotetext{
${ }^{3}$ Discussions with conference audiences and with colleagues related to dog blogs have alerted me to the fact that many people see the present data as extremely controversial and disconcerting, mainly because they seem to infantilize and demean the bloggers behind the blogs. These reactions - as well as the widespread practices of online flaming, trolling and harassment - call for caution. Therefore, an ethical decision here is in my view to protect the identities of the subjects by at least making it not so easy to trace back who the original authors of the blogs have been.

${ }^{4}$ At this point, it should be noted that all of these figures are approximations, based on my manual counting of blogs. This is because the Dogster site does not include a search engine that can reliably sort out the number of blogs by writers based in different countries.
} 
The blogs are written in a style that resembles traditional diary writing. Although the traditional diary is not a uniform genre in that it can include various sub-genres (e.g. notebooks, logs, confessional diaries, diaries with aesthetic goals) and styles of writing, even within one single diary (Sääksilahti 2011: 25), what all diaries have in common is that they are autobiographical in nature. Using the $1^{\text {st }}$ person narrative voice, they report and reflect, often in a detailed way, on aspects of the diarist's life and display an authenticity and frankness that is unlike writing done for publication (Maschuch 1996: 144-6). Further, diary writing, particularly in the $20^{\text {th }}$ century, is commonly associated with women and cultural processes whereby the everyday life and the home have become femininized (Bunkers and Huff, 1996: 3; Culley 1998: 217-8; see also Sääksilahti 2011: 31). As to personal blogs, it has been argued that in many respects they resemble diaries a great deal (see e.g. Herring et al. 2004), although, as Nardi and her colleagues (Nardi et al. 2004: 222) have pointed out, this view, too, does oversimplify the situation. This is because, they argue, there seems to be a great deal of variation of purposes, content, style within personal blogging, too. For example, according to their ethnographic studies, many personal blogs actually resemble radio shows more than personal diaries.

However, as far as blogging on dogs is concerned, a relatively conventional style of personal diaries seems a preferred mode, although, they, too, often have an explicit orientation to other readers besides the diarist-reader. The personal and private stance of dog blogs shows, firstly, in the way in which they often are explicitly designed as entries in a personal diary, with a $1^{\text {st }}$ person Singular voice. Further, in the same way as in traditional diary writing, typical topics dog blogs address include experiences, feelings, concerns, relationships and epiphanies in the diarist's life - with the exception that the diarist in dog blogs is a multi-voiced one - a human pretending to be a dog. The entries usually tell chronological stories about everyday life in which there are mundane, but from the dog's viewpoint, significant events and activities, such as playing, eating, training, and socializing with humans and other dogs, as well as confrontations and conflicts with humans, cats and other dogs. To these the dog is then described to react by accounts, typically written in an informal and intimate style, of what it feels and thinks about them. For instance, consider the ways in which example (1) from a blog featuring a US-based dog highlights such features ${ }^{5}$ :

$\mid$

\footnotetext{
5 The extracts from blogs are presented in their original form. The idiosyncratic expressions, typos and misspellings in them are thus not by the present author.
} 


\section{Example (1) - A US-based Tibetan Spaniel:}

man. Momma and I started obedience class last night. I am sorry to say that it was not our best showing. I am really scared of dogs I don't know...and my cute little tail that is usually curled up on my back was tuck, tuck, tucked between my legs! Yikes! Those other dogs, even the little ones were FRIGHTENING! I did a lot of growling and made "wookie" noises as momma calls them. (I guess I sound a lot like Chewbacca.) Anyway, another dog had the audacity to lunge at me - well, I tell ya, I snapped at him!! I nearly bit his nose. Ha! That'll show him!

At any rate, I did get really good at looking at momma's face. I paid really good attention! I even laid down and took a rest in class. We played a game called "come find me" too. I found my momma behind a big white sheet! Wicked cool!

Well, my friend Floyd just told me that we Tibetans are too smart for obedience. Yes! Wait until I go tell momma....

\subsection{Dogs using doggielect}

One of the clearest indications of the investment that the human ventriloquists make in dog blogging is how the blogs strive to create an impression of the actual style, a doggielect, in which dogs (could) talk and write. Example (2), an extract from a blog of a Philippines-based Shih Tzu, illustrates how this effect can be created:

Example (2) - A Philippines-based Shih Tzu

I can't pawlieve dogster actually made a section just us small breeds! PAWSOME!!! It's about time dogster paid tribute to us - the little ones!

I just found out a while ago when mommy opened up her email and saw the one about the new section on dogster. She was surprised to see it and me immediately. Of course, we checked it out. If I'm not mistaken, we're celebrating Patterdale Terriers today! Which is pawsome, cause they're small! Paws up for the little ones!

Anyways, if you wanna check it out (if you're small dog or a small dog lover, like my mommy) just click the link in between "news" and "add a dog". I hope you find it. :D Well, if not, I'll be nice to ya. Here's the link. Enjoy!

Yet again, thanks to HQ fur the great idea! And thanks also to Purina Mighty Dog fur the support! Pawlease check out their site! They made a special doggie food fur us little pups! 
In example (2), the doggielect consists of a combination of playful orthographic modifications (“pawlieve”, “PAWSOME”, “Pawlease”, “fur”), modified idioms (“paws up”). Further, as witnessed by all the other examples discussed in this paper, dogs seem to favour vernacular and informal spelling and style (“wanna”, “cause”), use syntactically simple sentences, and features indicating emphasis and emotionality (e.g. exclamation marks, upper case spellings). At the same time, such distinctive doggielect expressions are combined with text that, with a distinctly more formal and standard style and spelling, conveys an image of and comment on the human's actions, too: in this example, this shows in the way in which the dog is made to describe the actions of its owner ("I just found out a while ago when mommy opened up her email...”; "she was surprised to see it”).

That this kind of idiolect is something shared translocally and transculturally is shown in the next two examples, example (3) representing a US-based Cairns Terrier, and example (4) a Finlandbased Golden Retriever:

\section{Example (3): A US-based Cairns Terrier:}

Gwanma is comin! Gwanma is coming! She is coming all the way from a place called Florida and this will be my first time meeting her. I am so nervous that I am doing laps or as MJF says zoomies. Mom told me that she spoils her Grandfur children and actually gives out cheese! Can you believe it ...CHEESE! I think I overheard mom say something about giving me a bath..Gotta go hide now..Happy Summer everyone and keep close when your peeps do the grilling because they are bound to drop some tasty meat! Can you smell it? Here it comes..SUMMER!!

\section{Example (4): a Finland-based Golden Retriever}

Woof! It has been soooo cold here these days: -35'C or - 31F!!! When I went out today with my mami, my paws started hurting immediately, it was so cold. So I had to run back in really fast. Oh, it makes me a little bit sad that I can't go out well, and so I would like to play with my mami all the time...but of course, mamies always have so many things to do she can't play with me so much. But last weekend we had a lovely Sunday at one beautiful forest, we were walking there a lot and after we cooked some great sausages at one small hut (and I ate 2 whole sausages!), and it was soooo good! That was my best Sunday of the year!

Examples (3) and (4) are quite similar to the first two examples. Typical features of the doggielect again include modifications of standard orthographical forms and word play (e.g. "gwanma” and “Granddfur children”; ”sooo cold”, ”soooo goood”), canine’ wordings (“woof”), simple syntax and markers of emphasis and emotions (e.g. "sooo cold”, exclamations, upper case). All of these 
features could also be argued to suggest that the dog is somewhat childlike (e.g. the dog is unable to pronounce the [r]-sound). Along with the other means of impression building in these three examples (see below), these features highlight the dog's simple and naïve thought processes, emotions and interpretations (e.g. the description of excited responses to cheese or sausages). Thus, what we begin to see is an image of the dog as a hybrid creature: simultaneously canine, human and infantile.

Such deliberate crafting and dramatized performance of a distinctive style is, in fact, a good example of stylization, as defined by Rampton (2013: 361), as "reflexive communicative action in which speakers produce specially marked and often exaggerated representations of linguistic varieties that lie outside their habitual repertoire”. Why such stylization is called for in this site can have several explanations. Firstly, it may have something to do with the fact that stylization offers the bloggers a means to indicate that the blogs are to be seen as humorous and entertaining. Secondly, the bloggers' efforts to create an impression of a doggielect are, in principle, similar to the ways in fiction writers craft styles for their characters that contribute to them as particular kinds of personae, with particular kinds of relations, juxtapositions and tensions between them and other characters. In this sense, bloggers use the same means as such masters of fictional polyphony as Dostoyevski or Dickens (see, again Bakhtin 1993) for creating an impression of a particular kind of social world. In this respect, the stylistically heterogenous doggielect is particularly interesting in what it implies of the relationship between dogs and humans: even though the dog is granted a speaking voice and a way of speaking of its own, and thus some agency in the blogs, it also seems that the human is still depicted as the one that has the power to determine what the dog gets to comment on (e.g. eating cheese or sausages, going for walks in the snow). In other words, the humans are depicted to control over what the dog gets to and is allowed to do and say. In this way, the doggielect could be seen as simply a token gesture. Consequently, while the blogs assign dogs some agency, they actually use the dogs' voices to show to other dog lovers how well and responsibly the humans treat their dogs.

\subsection{Dogs as narrators and focalizers}

Besides the doggielect, another strategy used in the blogs that illustrates their ventriloquist agenda is how the updates of the dog's life are narrated as if by the dog itself, from its point of view, representing its experiences, thoughts, feelings and evaluations. Example (5), an extract from a UKbased German Shepherd is a case in point: 
Example (5) - a UK-based German Shepherd:

Ok, I have never written a diary before, usually my thoughts are wasted on my brother Obi. Mum woke us up at about 7.30 am today, had to laugh at her standing in the garden watching us do our business. It was raining buckets, she reckons she has to watch us cos I try to escape. Well Thats what she says! My skin brothers go to school and my skin sister is usually with mum, but today my brother came home again. Mum said he to go to the dentist, whatever that is. So our walk ws really short this morning, just an hour! Doesnt she realise I have needs too! There's bushes to sniff and alsorts, and you cant get mutch done in an hour! She went out for 2 hours, I got a little bored so decided to redecrota my crate, by redesigning my Duvet. It was my best work yet, but mum said nothing, and then, get this, she cleaned out my crate and put all the little fuzzy bits in the extra food box, (my mum calls it a bin, we aren't technically aloud in there, but hey.) All that hard work! Then around the time of the humans dinner, mum is chopping and washing all kind of tastey things, then that box rings, and mum goes to talk to it, (weirdo, it doont stop making that stupid noise till mum talks to it, I make noise and I get told thankyou, and then I feel I have to shut up) Well while she was comforting the ringing box, my furbrother obi got the good stuff of the high thing, and boy was that good. Mum seemed really cross about it, but we really did appreciate it. peppers taste good. well inner will be ready soon so I will sign of for now, chiao, $\mathrm{x}$

Example (5) illustrates a recurrent practice in the blogs in which the dog is presented as both the source of the words, the narrator, as well as the consciousness through which everything included in the blog is filtered to readers - its focalizer. In this example, the dog tells a chronological story of its day. This it does from the dog's subjective perspective, so that we are given access to ways in which the dog experiences, interprets and evaluates the humans, other dogs, and the events and actions described in the blog. Again, we notice that, in the same way as the doggielect, also the narration and focalization illustrated by example (5) aim to enforce the idea of the dog as both dogand humanlike. On the one hand, the blog refers to behaviour that is distinctly canine (e.g. sniffing) and wild (stealing food). In addition, example (5) shows how the dog's narration and thought processes are peppered by details that distinguish it from humans (e.g. it is not able to name and understand the phone or the table, or to comprehend that it destructive ripping of its duvet, its "work", is not appreciated by the humans). On the other hand, the dog is also described in very human terms, as for example having the capacity to analyse human behaviour ("Doesn't she realize I have needs too!”), and to make sophisticated distinctions between its species and the humans (“skinbrothers” vs. "furbrothers”). Thus, the human writer's voice can be detected in the details s/he chooses to include in the story to represent the dog's thoughts, emotions and perceptions. Once more, the author is depicting the dog, or, more specifically, its way of narration, as well as its perceptions, thoughts and emotions in a way that presents the dog as an entertaining, and to Dogster audiences at least, endearing creature that has both animal and human characteristics. 
Dogs are also crafted as rounded characters, with personality traits, peculiarities and preferences, and they self-evidently take the centre stage in their blogs. Interestingly, however, the blog also suggests that the human-dog relation is not entirely harmonious, as the dog is made to complain, for example, that it is not fully capable of understanding the human world, nor is its "mommy" fully able to understand the dog's instinctive needs. The otherness of the dog is thus not completely tamed - again, we thus hear the voice of the good and responsible dog owner who via the dog's voice tells other dog owners that, even though the diary format places the dog as the protagonist, narrator and focalizer, this does not mean that dog would cease to be an animal whose instinctual wildness s/he also needs to appreciate.

\subsection{Dog as a (naughty) child of the responsible middle class mother}

It is no doubt obvious by now that there is a tendency in dog blogs to characterize dogs as sweet, sensitive, and intelligent, albeit infantile, creatures which are eager to interact with their human companions. Example (6) - an extract from a blog on a Finland-based dog also illustrates these qualities of dogs:

\footnotetext{
Example (6) - A Finland-based French Boxer

Today i went to see my dog cousin (my human moms brothers german shepperd) We played and played. Eaven if he is so big compared to me, i keep him in order. I learned it from my real mom. [...] When we got back in the car, i was so tired that i was just sleepping. But $\mathrm{i}$ think that my mommy got some bones from santa advanced. I could smell through the bag that there were some bones wrapped in the papers. So i must have been good. Well, some bad things i have done but mommy forgave me already. I broke the remotecontrol of tv ( $i$ was trying to put the tv on cause i was bored) $i$ jumped on the table and dropped some bowl down and broke it ( $\mathrm{i}$ was just trying to smell what was in it ), i opend the capord in the bathroom and $\mathrm{i}$ took mommys "wemen staff" and teared paggages, bited tubes and tasted evrything (wanted to have a girlsday with my mom ) i got in to toilet and i took all pakage of toiletpaper and teared them around the apartment ( well , i was just bored but atleast i made my mommy to laugh)But otherwise i have been real good and santa will give me presents i know :-)
}

Like all the other examples discussed so far, this extract not only includes descriptions of the dog and its life, but it also refers to and evaluates the actions of the dog's significant human other. These often take the form of explanations of how s/he tries to control, train and pamper the dog, and of what s/he thinks about the events and activities the dog engages in. In most blogs of my data, the 
significant other is the female owner of the dog, referred to as "Mamma”, Mama”, "Mummy”, "mom" or "Mami". In these ways, dog blogs emphasize that they are really of interest to women (who love dogs), and that the relationship between the female owner and the dog is considered similar to the one between a mother and a child.

The description in example (6) of the mother-child relationship between the female dog owner and the dog is a case in point: it illustrates how dog blogs position the female dog owner as the mother of the canine child in the private realm of her domestic life. In this example, the dog is also presented as a particularly naughty child - not an untypical characterization in dog blogs - creating havoc, ripping and destroying things. Nevertheless, the dog-child seems confident that whatever naughtiness (i.e. animal-like behaviour) it engages in, it will be forgiven. The mother is thus depicted as a good, understanding and loving one. No doubt, in such a depiction we can again detect a moral validation of the dog owner as someone who truly cares for her pet. This kind of recurrent emphasis on the mother-canine dog relationship in the blogs is a good example of what social psychological research has posited about the relationship between women and dogs in cultures that value dogs. For example, it has shown that women (especially women who do not have children living with them) are more likely than men to develop strong bonds with their companion animals and to develop "mothering" and "nurturing" relationships with them (Kellert and Berry 1987; Margolies 1999; Turner 2001). The fact that such bonding is nowadays also featured in social media could, in turn, be seen as an example of the ways in which young women are increasingly featuring their private lives, families and everyday activities in their public 'homing' blogs (Jäntti and Järvinen 2014).

The blogs also suggest that the dog is a full member of the human family. Examples (7) and (8) give further evidence of dogs not only children, but also of their role as members of the family:

\section{Example (7) A UK-based Great Dane}

This is brill, we've found out that the pawrents are off on holiday on Saturday and are leaving us at home for a WHOLE WEEK!! Our Auntie Heather is coming to look after us while they're gone. How fab is that! She spoils us rotten and lets us do all sorts of stuff that THEY won't.

I guess I will miss my mummy, yes of course I will. But having Auntie Heather for a whole week ..... bliss!

Example (8): A Finland-based Boxer 
I've been super busy for weeks now. The reason for this is that I have become A BIG SISTER! Mummy's tummy finally showed us the stowaway that had been hiding there for months, and now I have a funny little creature as a sister! Her name is Heini and she is six weeks old. Guarding her is a full-time job, because she doesn't know that many things as of yet.

First of all, she is not house-trained yet. It only took me two weeks to learn, but Mummy tells me it can take up to two years with Heini. Two YEARS! Also, she doesn't eat solids yet, not even my meatiest, juiciest bone that I gave her when she came home from the hospital. Had to eat it myself, a good bone is hard to find you know... [...]

The outcome of all this is that I need to instruct, guard and protect for most of the day. But what can you do, one needs to support one's family! And on the other hand, Heini is kinda sweet and very LICKABLE!

Better go and check on her. Maybe she has woken up while I was typing this... Ciao!

Both examples (7) and (8) describe the identities of and relationships between dogs and humans. Dogs refer to humans as "pawrents”, “Aunties” and "sisters” and indicate that they have a humanlike emotional bond with them. Example (8) goes as far as equate the human child with dog puppies, and presenting the dog as the instructor, guardian and protector of the baby who is not "house-trained yet". Essentially there is thus no fundamental difference or clear-cut borderline between the humans and the animals, and the blogs play with the imagined parallels and contrasts between them.

Further, the mothers, families and lifestyles depicted in the dog blogs are often of a particular kind. As was suggested in the beginning of this article, dog blogs can be seen as a technology of the self, whereby selves are manufactured and fashioned with particular discursive resources. So far I have argued that as a technology it seems particularly useful to and popular among women, but, on the basis of my data, it also seems that the women to whom it has most appeal are those who (aspire to) identify with and index a middle class orientation. The connection between dogs and class in the blogs echoes, in fact, a more general observation about attitudes to companion dogs. That these attitudes are indexical of class identifications has been confirmed, for example, by recent work in cultural sociology (e.g. Blouin 2009; Terries forthcoming). According to these studies, dog owners fall into different social categories (Blouin 2009). For example, people from rural backgrounds tend to view dogs more as guardians that should be kept outside, whereas more affluent people tend to see their pets more as children (Terries forthcoming) .

With respect to dog blogs, I consider class as primarily a set of 'correct' cultural resources with which people are required and strive to become "subjects with value” (Skeggs (2004: 77) and with which they can articulate a class orientation (Bourdieu 1984: 175-176, 1998:4-6). In the 
blogs, particularly interesting resources in this sense include, for example, the ways in which they describe how dogs are treated, as well as the images of dogs associated with the blogs.

Firstly, the blogs frequently emphasize the meticulous ways in which dogs are taken care of. For example, dogs are allowed to live inside and, as was noted above, are treated as full members of the family. Further, they are carefully groomed, doctored, exercised, trained, pampered with expensive accessories and toys, and given elaborate birthday parties. Generally dogs are given the same kind of care as human children would be. Some of this care taken shows in example (9) in which the preparations for a birthday party are described by a US-based Shih Tzu:

\section{Example (9): A US-based Shih Tzu}

Well momma got us all dressed up today and took us to a barkery! We think its where you get baked goods for doggies because we seen all these collars and dog food bags etc.

Momma got this special box full of goodies and hid them in the fridge. Plus I seen her buy Bert some birthday squeeky balls and put them up in the cabinet. Now im sorry but that dont seem right to me! When momma and daddy buys us toys we normally get them that day!

Now why didnt she give them to us? I heard the B word a couple times and heard gingers and hennessee's name mentioned along with fruit smoothies... hmmmm

I heard them say the number 1 , could that be it? im 11 months old not 1 month old whats up with dat!?

Only time will tell then I suppose...... well im off to tell bubby the secret about his balls BOL

Similar attention to the dog's needs and willingness to invest in its wellbeing is also evident in example (10) that describes how a Philippines-based dog gets its own nanny:

Example (10): A Philippines-based Basset Hound

Hi all! I haven't been able to write for some time. My momma and pappy-uh have been very busy. Since the beginning of New Year, so much has happened. Starting the year with momma's pregnancy and pappy-uh getting sick, I haven't been able to get my daily walks and sniffs. Life has been so borriiiing!

But not lately! Because you know what...my pappy-uh got me my very own...NANNY! Well, she's not really entirely mine...but I think she wants to be. She helps momma out with the house chores and errands that need to be taken care of. Anyway, she is so nice to me and gives me walks at least $4 x$ a day! I think I'm her 
priority. We even go as far as the old lady's house down the street. Although momma told nanny not to go farther than that because there's a vicious dog that keeps attacking me there. I'm fine with that.

So, life is back to normal for me...and even better!

-spoiled dog

The styles in which dogs are visually represented in the context of their blogs could also be seen as indexing a middle class orientation. For instance, consider the following pictures - they, too, show the meticulous attention paid to dogs - grooming, clothing, giving them expensive gifts. The anthropomorphic intention in these pictures in also very clear: the dogs are represented, dressed up and accessorized (in often gender-specific ways) in the same way as humans would be:
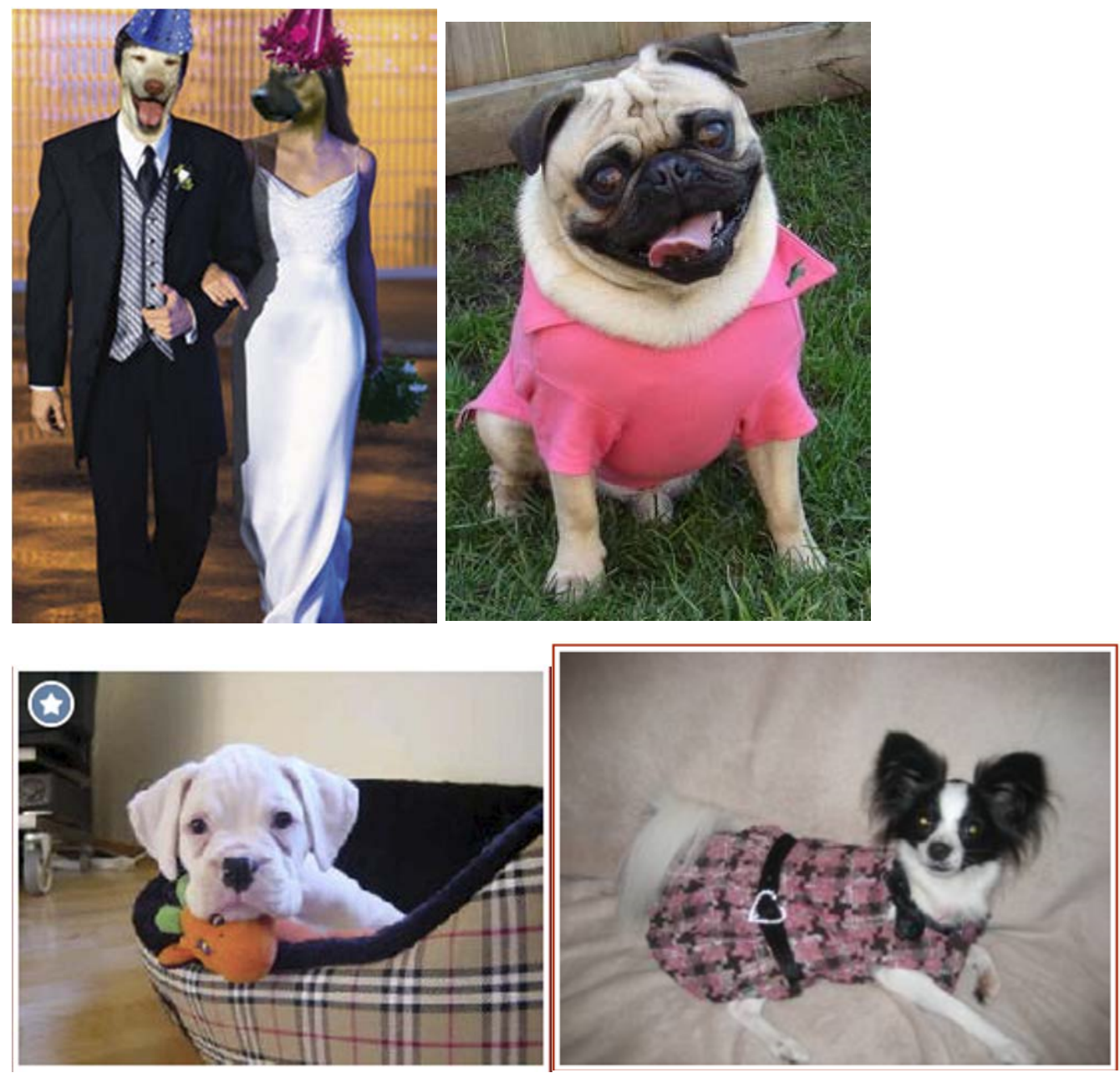

Interestingly, gendering the dogs into distinctly feminine and masculine dogs does not seem to be very typical in the written parts of the dog blogs. This may be due to the fact that most dog blogs written in the dog's voice tend to infantilize the dogs - so, rather than gender, it is their 'child- 
likeness' that is emphasized. Gender also intertwines with breed: for example, smaller dogs are often seen as cuter and more adorable (and thus, more feminine), regardless of their sex.

\section{IN CONCLUSION: HUMANS ANTHROPOMORPHIZING DOGS - DOGS AUTHENTICATING HUMANS}

In sum, the case of dogs blogging was used in this paper to highlight the ways in which in a translocal and transcultural social media niche where the participants who know very little or nothing about each other, in order to authenticate themselves and others draw on and index a shared discursive orientation. My analysis showed that in order for such authentication to work, there needs to be a consensus on the value and relevance of such an orientation, as well as some form of collective uptake. In dog blogging, this was shown to be the case: dog bloggers from different geographical, cultural and linguistic contexts of the world were shown to rely on and apply very similar conventions and norms for crafting their blogs.

More specifically, my analysis demonstrated that the particular ways in which dog bloggers strive to achieve an impression of authenticity involves a complex of linguistic and discursive strategies, including the use of the generic conventions of the personal diary, a particular set of linguistic features collectively imagined and enforced as characteristic of dogs, the presentation of the dog as the first person narrator-focalizer, and the characterisation of the dog as a true hybrid dog-child of the middle class mother. The discourse of dog blogs was shown to rely crucially on stylization, the imaginative simulation of a dog's voice, as well as on ventriloquism, the creation of double-voiced discourse in which the description of dogs, their characteristics and their stories functioned as means for human writers to gain and maintain their access to and rights to participate in the social sphere of the global dog lovers in Dogster. In a way, it could be argued that in dog blogging, the human bloggers are using the voice and perspective of another - in this case, of the dog - to authenticate themselves as legitimate participants in dog blogging. This kind of view actually means that authentication is fundamentally reflexive and social practice -something that can actually be true of authentication more generally.

However, this not all there is to say about authentication in dog blogging, for dog blogging is not only about legitimate participation rights, but also about moral authentication. As was shown above, one of the most striking features of dog blogs is that they depict dogs as (at least partly) human-like, thinking and feeling beings. In doing this, they are not alone, but draw on and recycle conventions 
that we are familiar with from history, fiction, film and popular culture. For example, it has long been a feature of the cultures that value dogs that humans, women, in particular, tend to treat their dogs as if they possess human capabilities (Mithen 1996; Myers and Saunders 2002; Serpell, 2005), believing that their pets genuinely love or admire them, miss them when they are away, feel joy at their return, and are jealous when they show affection for a third party (Serpell 1996: 141-3). In this respect, there seems thus to be nothing particularly new about dog blogs - they are digital versions of an age-old, pervasive tendency for humans to anthropomorphize their companion animals. Thus the blogs effectively reproduce and reaffirm this existing, and largely western, discourse about dogs.

In a way, the pervasiveness and longevity of such discourse in dog blogging is all the more striking, because anthropomorphism has recently been strongly criticized as non-ethical and harmful by philosophers, animal activists, and even dog breeders. The criticisms against anthropomorphism, also voiced in many popular guidebooks nowadays (see, e.g. the discussion in Horowitz 2009: 2946) means that by now they must be familiar to many dog owners, too. On the whole, as argued by Markovits and Queen (2009: 326), in all the countries of the advanced industrial world, anthropomorphism is beginning to be challenged and replaced by views which insist on treating animals, dogs, in particular, in terms that do not build on a view of them as similar to humans. A view like this is also strongly advocated by the philosopher Donna Haraway (2003: 11-2):

[C]ontrary to lots of dangerous and unethical projection in the Western world that makes domestic canines into furry children, dogs are not about oneself. [...] They are dogs, i.e. a species in obligatory, constitutive, historical, protean relationship with human beings.

Why anthropomorphism still continues to be such a pervasive discourse practice in a context like dog blogs may, however, be motivated, besides by the fact that it can provide bloggers with useful, sharable and transparent resources for authentication, because the blogs are not only about dogs, but also - and perhaps more importantly - about humans. In this sense, the anthropomorphic discourse the bloggers draw on does not only serve them as a resource to represent dogs as human-like, but also to represent humans as dog-like. In fact, I would like to argue that the blogs promote a particular idealised version of (dog loving) human beings, especially of women, and their identities, lifestyles and values. In their own way, they convey an image of what makes life meaningful and fulfilling: experiencing and enjoying life to the full in the domestic context: family, friends, good 
meals, get-togethers, festivities, nature, play, material comforts, selfless love. In this picture, then, dogs are the kind of creatures also human beings should be. This kind of a promotion of ideal identities and lifestyles can, however, also be seen as highly disciplinary and political: especially in relation to women, it seems to suggest that a traditional, middle-class, home-centred, domestic lifestyle and identity are ones that best ensure a happy and balanced life for them.

To conclude, I have demonstrated how the authentication practices that participants in dog blogging engage in and collaboratively ratify runs deeper than simply ensuring their access and legitimacy in participating in dog blogging in convivial ways. Importantly, dog blogging also involves the authentication of humans with particular values and ideologies: humans who can also index to others that their orientation to both dogs and humans is morally, socially, culturally, and even politically, the kind expected by other like-minded (dog loving) humans.

\section{Acknowledgements}

I'm very grateful to the Aaltonen Foundation for giving me the opportunity to concentrate on writing my paper and editing the special issue. I also wish to thank The Faculty of Humanities at University of Jyväskylä for making it possible for our research group to organize one of our preparatory seminars with the Amager project team in Copenhagen. Most of all, I thank the Jyväskylä and Copenhagen teams for the genuine spirit for collaboration, inspiring discussions, and good cheer. It was a great ride! Jens Normann, this is for you! 


\section{REFERENCES}

Arnaut, K. 2012. Super-diversity: elements of an emerging perspective. Language and

Superdiversities II, Diversities 14:2, pp. 1-16.

Bakhtin, M. \& Caryl Emerson. 1993. Problems of Dostoevsky's poetics. Minneapolis: University of Minnesota Press.

Blommaert, J. 2010. The Sociolinguistics of Globalization (Cambridge: CUP.

Blommaert, J., S. Slembrouck \& J. Collins. 2005. Polycentricity and interactional regimes in 'global neighborhoods'. Ethnography June 6, pp. 205-235

Blommaert, J. \& P. Varis. 2013. Enough is enough: The heuristics of authenticity in superdiversity. In Duarte, J. \& I. Gogolin (eds.), Linguistic Superdiversity in Urban Areas: Research approaches 2, pp. 143-160.

Blood, R. 2002. Introduction. In Rodzvilla, J. (ed.), We've got Blog. Cambridge: Perseus Publishing, pp. ix-xiii.

Blouin, D. 2009. A Dog's Life: Relationships Between Dogs, Owners Fall Into Three Categories. ScienceDaily, 19 August 2009. www.sciencedaily.com/releases/2009/08/090810025813.htm, accessed April 16, 2015.

Bonas, S., J. McNicholas and G.M. Collins. 2000. Pets in the Network of Family Relationships: An empirical study. In Podberscek, A.L., E. Paul and J.A. Serpell (eds.). Companion Animals and Us. Cambridge: CUP.

Bourdieu, P. 1984 [1979]. Distinction: A Social Critique of the Judgement of Taste. Trans. Richard Nice. Cambridge, MA: Harvard University Press.

Bourdieu, P. 1998b. [1994]. Practical Reason: On the Theory of Action. Stanford, CA: Stanford University Press.

Bruns, A. 2008. Blogs, Wikipedia, Second Life, and Beyond. From Production to Produsage. New York: Peter Lang.

Bucholtz, M. 2003. Sociolinguistic nostalgia and the authentication of identity. Journal of Sociolinguistics 7:3, pp. 398-416.

Bucholtz, M. and K. Hall. 2004. Language and Identity. In A. Duranti (ed.), A Companion to Linguistic Anthropology. Oxford: Basil Blackwell, pp. 369-394.

Bunkers, S.L. \& C.A. Huff. 1996. Issues in studying women's diaries: Theoretical and critical introduction. In Bunkers, S.L. and C.A. Huff (eds), Inscribing the Daily: Critical Essays on Women's Diaries. Amherst: University of Massachusetts Press, pp. 1-22.

de Certeau, M. 1988. The Writing of History (Trans. Tim Conley). New York: Columbia University Press.

Connor, S. 2000. Dumbstruck: A Cultural History of Ventriloquism. New York: Oxford University Press.

Coupland, N. In press. Language, society and authenticity: Themes and perspectives. In Lacoste, V., J. Leimgruber \& T. Breyer (eds.) Indexing Authenticity: Sociolinguistic Perspectives. FRIAS Linguae \& Litterae series. Berlin, Germany: Mouton de Gruyter.

Culley, M. 1998. Introduction to A Day at a Time: Diary literature of American women, from 1764 to the Present. In Smith, S. \& J. Watson (eds), Women, Autobiography, Theory. A Reader, Madison \& London: The University of Wisconsin Press, pp. s. 217-221.

Daston, L. 2005. Intelligences: Angelic, Animal, Human. In Daston, L. \& G. Mittman (eds.) Thinking with Animals: New Perspectives on Anthropomorphism. New York: Columbia University Press, pp. 18-36.

Daston, L. and G. Mitman (eds). 2005. 'Introduction.’ In Daston, L. \& G. Mittman (eds.) Thinking with Animals: New Perspectives on Anthropomorphism. New York: Columbia University Press, pp. $1-14$. 
Foucault, Michel. 1988. Technologies of the Self. A seminar with Michel Foucault. Edited by Martin, L. H. Martin, H. Gutman and P. H. Hutton (eds), pp. 16-49. Amherst: University of Massachusets Press.

Garber, M. 1996. Dog love. New York: Simon \& Schuster

Gee, James P. 2005. Semiotic Social Spaces and Affinity Spaces: From The Age of Mythology to Today's Schools. In D. Barton \& K. Tusting (eds.), Beyond communities of practice: Language, power and social context. Cambridge: Cambridge University Press, pp. 214-232.

Haraway, D. 2003. The Companion Species Manifesto: Dogs, People and Significant Otherness. Chicago: Prickly Paradigm Press.

Herring, S., L. Scheidt, S. Bonus \& E. Wright. 2004. Bridging the gap: A genre analysis of weblogs. Proceedings $37^{\text {th }}$ Annual HICSS Conference. Big Island, Hawaii.

Horowitz, A. 2009. Inside of a Dog: What dogs see, smell, and know. New York: Scribner. Häkkinen, A. \& S. Leppänen. 2014. YouTube Meme Warriors: Mashup Videos as Satire and Interventional Political Critique. eVarieng 15, http://www.helsinki.fi/varieng/series/volumes/15/, accessed January 15, 2015.

Jacklin, M. 2005. Spitting the dummy: Collaborative life writing and ventriloquism, New Literature Review, no 43, 2005, pp. 67-81.

Jäntti, S. \& S. Järvinen. 2014. Kotiblogien julkiset käpertymisen maisemat ('The public landscapes of curling up in homing blogs'). In Sarems, T. and S. Jäntti (eds.) Maisemassa: Sukupuoli suomalaisuuden kuvastoissa ('In the landscape: Gender in the imageries of Finnishness'). Jyväskylä: Centre for the Study of Contemporary Culture, pp. 217-248.

Katz, J. 2003. The New Work of Dogs. New York: Villard.

Kellert, S. \& Berry, J. (1987). Attitudes, knowledge and behaviors toward wildlife as affected by gender. Wildlife Society Bulletin, 15, pp. 363-371.

Kramsch, C. 2012. Imposture: A Later Modern Notion in Poststructuralist SLA research. Applied Linguistics. 33:5, pp. 483-502.

Kytölä, S. 2013. Multilingual language use and metapragmatic reflexivity in Finnish online football forums. A study in the sociolinguistics of globalization. A published doctoral dissertation, Department of Languages, University of Jyväskylä.

https://jyx.jyu.fi/dspace/handle/123456789/41042, accessed January 4, 2015.

Kytölä, S. Forthcoming. Translocality. In Georgakopoulou, A. \& T. Spilioti (eds.), Handbook of Language and Digital Communication. London: Routledge.

Kytölä, S. \& E. Westinen. 2015/This issue. “I be da reel gansta” - a Finnish footballer's Twitter writing and metapragmatic debates on authenticity. Discourse, Context and the Media.

Leppänen, S. 2008. Cybergirls in trouble? Fan fiction as a discursive space for interrogating gender and sexuality. In C. R. Caldas-Coulthard and R. Iedema (eds.) Identity Trouble: Critical Discourse and Contested Identities. Basingstoke: Palgrave Macmillan, pp. 156-179.

Leonard, S.P. 2014. The Polar North: Ways of speaking. Ways of belonging. London: Francis Boutle Publishers.

Leppänen, S. 2009. Playing with and policing language use and textuality in fan fiction. In HotzDavies, I., A. Kirchhofer and S. Leppänen (eds.) Internet Fictions. Cambridge: Cambridge Scholars Publishing, pp. 62-83.

Leppänen, S. 2012. Linguistic and discursive heterogeneity on the translocal internet: the case of web writing. In Sebba, M., S. Mahootian and C. Jonsson (eds.) Language Mixing and Codeswitching in Writing: Approaches to Mixed-language Written Discourse. London: Routledge, pp. 233-254.

Leppänen, S. and A. Häkkinen. 2012. Buffalaxed superdiversity: Representations of the other on YouTube. Diversities. A special issue on sociolinguistics and superdiversity, ed. by Blommaert, J., B. Rampton, K. Arnaut \& M. Spotti.2012, 14: 2, pp. 17-33, UNESCO.

www.unesco.org/shs/diversities/vol14/issue2/art2, accessed November 12, 2014. 
Leppänen, S., H. Jousmäki, S. Kytölä, S. Peuronen \& E. Westinen. 2014. Entextualization and resemiotization as resources for identification in social media. In Seargeant P. \& C. Tagg (eds.). The language of social media: communication and community on the internet. Basingstoke: Palgrave, pp. 112-138.

Leppänen, S. and S. Kytölä. Forthcoming. Investigating multilingualism and multi-semioticity as communicative resources in social media. In Martin-Jones, M. \& D. Martin (eds.), Researching Multilingualism: Critical and Ethnographic Approaches. London: Routledge.

Leppänen, S. \& P. Pahta. 2012. Finnish language endangered - language ideological debates about English in the Finnish press from 1995 to 2007. In Blommaert, J., S. Leppänen, P. Pahta \& T. Räisänen (eds.) Dangerous Multilingualism: Northern Perspectives to Order, Purity and Normality. Basingstoke: Palgrave Macmillan, pp. 142-175.

Leppänen, S. \& A. Piirainen-Marsh. 2009. Language policy in the making: an analysis of bilingual gaming activities. Language Policy, 8(3), pp. 261-284.

Leppänen, S. A. Pitkänen-Huhta, A. Piirainen-Marsh, T. Nikula, T. \& S. Peuronen. 2009.

Young people's translocal new media uses: A multiperspective analysis of language choice and heteroglossia. Journal of Computer-Mediated Communication, 14 (4), pp. 1080-1107.

Leppänen, S, A. Pitkänen-Huhta, T. Nikula, S. Kytölä, T. Törmäkangas, K. Nissinen, L. Kääntä, T. Räisänen, M. Laitinen, P. Pahta, H. Koskela, S. Lähdesmäki \& H. Jousmäki. 2011. National Survey on the English Language in Finland: Uses, Meanings and Attitudes. Helsinki: Research unit for the variation, contacts and change in English. http://www.helsinki.fi/varieng/journal/volumes/05, accessed January 2, 2015.

Margolies, L. 1999. The long good-bye: Women, companion animals, and maternal loss. Clinical Social Work Journal, 27: 3, pp. 289-304.

Markovits, A. S. \& , R. Queen. 2009. Women and the World of Dog Rescue: A Case Study of the State of Michigan. Society and Animals 17, pp. 325-342.

Maschuch, M. 1996. Origins of the Individualist Self: Autobiography and Self-Identity in England, 1591-1791. Stanford: Stanford University Press.

Mithen, S. 1996. The prehistory of the mind: A search for the origins of art, religion and science.

London: Thames and Hudson.

Myers, G. 2010. The discourse of blogs and wikis. London: Continuum.

Myers, O. E. \& C. D. Saunders. 2002. Animals as links toward developing caring relationships with the natural world. In P. H. Kahn \& S. R. Kellert (eds.), Children and nature: Psychological, Sociocultural, and Evolutionary Investigations. Cambridge: MIT Press, pp. 152-178.

Nardi, B. A, D. J. Schiano \& D. M. Gumbrecht. 2004. Blogging as Social Activity, or, Would You Let 900 Million People Read Your Diary? CSCW '04 Proceedings of the 2004 ACM conference on Computer supported cooperative work, pp. 222-3.

Nørreby T. R. \& J Spindler Møller. 2015/This issue. The use of identity categories related to ethnicity in on- and offline interaction among Copenhagen adolescents. Discourse, Context and Media.

Pietiläinen, P. 2013. Koirien maailmanhistoria ('The dogs' world history'). Helsinki:SKS.

Rampton, B. 1999. 'Deutsch in Inner London and the animation of an instructed foreign language,' Journal of Sociolinguistics 3, pp. 480-504.

Rampton, N. 2006. Language in Late Modernity: Interaction in an urban school. Cambridge: CUP. Rampton, B. 2013. Styling in a Language Learned Later in Life. The Modern Language Journal, 97: 2, pp. 360-382.

Serpell, J.A. 1996. In the Company of Animals. Cambridge: CUP.

Skeggs, B. 2004. Class, Self, Culture. London: Routledge.

Staehr, A. 2015/This issue. Metapragmatic activities on Facebook - Enregisterment across written and spoken language practices. Discourse, Context and Media.

Sääskilahti, Nina. 2011. Ajan partaalla: Omaelämäkerrallinen aika, päiväkirja ja muistin kulttuuri. 
('On the brink of time: autobiographical time, diaries and the culture of memory'). Ph.D. Thesis. University of Jyväskylä. https://jyu.finna.fi/Record/jykdok.1245516, accessed April 15, 2015. Terries, E. Forthcoming. Urban Cultural Conflict and Community Identity. Ph.D. Thesis. University of Chicago.

Thurston, M.E. 1996. The Lost History of Canine Race: Our 15 000-year love affair with dogs. New Jersey: Andrews and McMeel.

Turner, W.G. 2001. Our New Children: The Surrogate Role of Companion Animals in Women's Lives. The Qualitative Report, 6: 1, http://www.nova.edu/ssss/QR/QR6-1/turner.html, accessed March 20, 2014.

Walker Rettberg, J. 2013. Blogging. Cambridge: Polity Press.

Varis, P. and X. Wang. 2011. Superdiversity on the Internet: A Case from China. Diversities, 13: 2, www.unesco.org/shs/diversities/vol13/issue2/art5, accessed January 16, 2014, pp. 70-83.

\section{Bionote}

Sirpa Leppänen is a Professor at the Department of Languages at University of Jyväskylä, Finland. With her research team (http://www.socialmediadiscourses.fi/ ), she investigates the ways in which resources provided by languages, other forms of semiosis and discourses are used by individuals and groups in social media and the ways in which such resources are used for social action and cultural production. 